\title{
A CONTRIBUIÇÃO DOS CATADORES DE LIXO PARA A FORMAÇÃO DE UMA EDUCAÇÃO AMBIENTAL NO SEMI-ÁRIDO NORDESTINO DO BRASIL
}

\author{
Luan Gomes dos Santos de Oliveira ${ }^{1}$ \\ Geovânia da Silva Toscano² \\ Ramiro Gustavo Valera Camacho ${ }^{3}$ \\ Gilcélia Batista de Góis ${ }^{4}$
}

\begin{abstract}
Resumo: Nosso estudo tem como referência a Associação Comunitária Reciclando para a Vida (ACREVI), situada na cidade de Mossoró/RN, no Bairro Nova Vida. Analisase quais as concepções de Educação Ambiental dos associados da ACREVI no ano de 2009. Como procedimentos metodológicos realizamos revisão, pesquisa de campo que teve como instrumentos as seis entrevistas semiestruturadas e a observação in lócus. Identificamos que para os sujeitos entrevistados a Educação Ambiental é reconhecida como uma ferramenta que é desenvolvida através da coleta seletiva e da realização de palestras nas empresas acerca do tratamento do lixo, como também pelo teatro. Tratase de uma investigação realizada no final da Graduação em Serviço Social na Universidade do Estado do Rio Grande do Norte. (UERN) concluída em 2009.
\end{abstract}

Palavras-chave: Questão Socioambiental; ACREVI; Catadores de Lixo.

\begin{abstract}
${ }^{1}$ Docente e Assistente Social do curso de Serviço Social da Universidade Federal de Campina Grande/UFCG, Coordenador do Grupo de Estudos Transcender (GRUT), Mestre em Desenvolvimento e Meio Ambiente - UFRN. Email: luangomessantos@terra.com.br

${ }^{2} \mathrm{Dr}^{\mathrm{a}}$ em Ciências Sociais - UFRN. Docente do Departamento de Ciências Sociais da Universidade Federal da Paraíba/UFPB. Lider do Grupo de Pesquisa Ciências Sociais. Cultura e Educação (UFPB). Email:geotoscano@gmail.com.

${ }^{3}$ Dro em Ciências (Área de concentração Botânica) pelo Instituto de Biociências -IB, da Universidade de São Paulo - USP (2001). Atualmente é Professor adjunto IV do Departamento de Ciências Biológicas DECB e participamos do Programa Regional de Pós-Graduação em Desenvolvimento e Meio Ambiente PRODEMA da Universidade do Estado do Rio Grande do Norte-UERN. Email: ramirogustavo@uern.br.

${ }^{4} \mathrm{Dr}^{\mathrm{a}}$ em Ciências Sociais pela Universidade Federal do Rio Grande do Norte (2013). Professora adjunta III da Universidade do Estado do Rio Grande do Norte. Tem experiência na área de Geografia, com ênfase em Teoria do Desenvolvimento Regional, atuando principalmente nos seguintes temas: Avaliação de políticas públicas. Formação profissional, Assentamentos rurais, atualidade e exclusão social. Professora do programa de Pós-graduação em Serviço Social e Direitos sociais da UERN. Vice líder do Grupo de pesquisa sobre políticas públicas (GEPP-UERN) e membro do grupo GIAPP_UFRN.
\end{abstract}

Revbea, São Paulo, V. 10, № 3: 97-110, 2015. 


\section{Introdução}

Na tessitura desta diversidade, cremos que o maior desafio da EA se ajusta na busca da alteridade - no respeito aos diferentes. É preciso desejar a transformação social através da participação de ideias plurais contidas na essência reflexiva para uma Terra com mais responsabilidade ecológica (Michèle Sato e Luiz Augusto Passos).

Ancorando-se na epígrafe que abre o texto, propomos a leitura deste trabalho para a formação de cultura de diálogo, capaz de descobrir as riquezas em cada autor e leitor, escritos no texto desta vida. Se faz assim necessário uma postura plural para criar um caminho único, onde haja o triunfo da Unidade e da compreensão mútua de que não vivemos sós nesta Terra. Este trabalho que ora vos apresentamos está dentro deste contexto de criatividade e de diálogo.

Toma-se como escolha teórico-metodológica a perspectiva teórica da Educação Ambiental dialógica ou contextualizada que tem como principal expoente o Educador Paulo Freire, defendida pelo Prof ${ }^{\circ}$. Dr. João Figueiredo (UFC). Para Figueiredo (2003) a Educação Ambiental dialógica, significa atender a princípios como a interdisciplinaridade, o diálogo democrático, compreender o aprendente como autor ativo e a contextualização como essencial no processo educativo; a supra-alteridade que valoriza o outro como legítimo outro; o saber parceiro, entre outros.

Nosso estudo diz respeito a compreensão da prática da Educação Ambiental de alguns atores residentes na cidade de Mossoró/RN onde são produzidas 148 toneladas de lixo das quais só $15 \%$ são aproveitadas para 0 processo de reciclagem. Esses atores por vezes invisibilizados no tratamento do lixo, foram sujeitos de nossa curiosidade por constatarmos que eles atuam ativamente na coleta seletiva, na reciclagem e na produção de artesanato como material reciclável, mas que seu trabalho é visto de maneira precária e excludente.

Como questão de pesquisa apontamos: como a Educação Ambiental contribuiu com as ações dos catadores de lixo organizados em associações no município de Mossoró/RN, pólo da região do Oeste Potiguar?. Analisamos a concepção de Educação Ambiental a partir das ações empreendidas pelos catadores associados, enquanto agentes de EA, organizados na Associação Comunitária Reciclando para a Vida (ACREVI) em Mossoró/RN da região do Oeste Potiguar. Por meio de uma análise interdisciplinar, investigamos os limites e potencialidades das ações dos catadores no processo de gestão de resíduos sólidos naquela cidade.

Diante de uma denominada crise da racionalidade científica apontada por por alguns autores dentre eles Enrique Leff, Edgar Morin, Boaventura 
Santos, trabalhamos com a perspectiva da Educação Ambiental Popular, que tem como principal aporte teórico a perspectiva freireana, pelo fato de encontrarmos nela, tanto uma interpretação crítica da realidade, como o resgate do sentido das experiências da vida dos sujeitos envolvidos com a pesquisa, e por apostar no diálogo entre a epistemologia e os saberes populares.

\section{A questão socioambiental, educação ambiental crítica e a dimensão popular na cidade de Mossoró (RN)}

A relação entre o ambiente e a sociedade é pautada no modelo de dominação, onde o homem vê a natureza enquanto recurso ou propriedade. Muitos pesquisadores da área ambiental como Foladori (1999) denunciam em suas obras que as raízes da questão ambiental concentram-se na relação desequilibrada entre a sociedade e a natureza que marca a gênese do sistema capitalista, provocando o esgotamento dos recursos naturais.

Assim, verificamos que o contexto socioambiental é complexo e por isso exige a articulação de múltiplas dimensões que constituem a realidade social, dentre as quais estão a cultural, a política, a econômica, a educacional e a socioambiental. Em virtude disso, é necessário enfatizar que em várias partes do planeta, como na França, a emergência da questão ambiental se dá de forma brusca em maio de 1968, com o alavancamento do movimento industrial.

Soffiati (2002, p.45) nos diz que as "crises ambientais ocorreram na China Antiga, na llha de Páscoa, na civilização Maia, na civilização Inca, na civilização khmeriana, na civilização grega etc". Mas precisamos saber que essas crises aconteceram por fenômenos de ordem climática, geológica e não por ações antrópicas. Soffiati (2002) também nos explica que a terra ao longo de sua história passou por vários processos de hecatombes, as quais se manifestaram de forma contundente nas chamadas eras/períodos geológicas.

Em 1962, Rachel Carson, quando publica o livro "A Primavera Silenciosa", passa a tornar público os agravamentos do uso de pesticidas e de intensivos químicos no modelo de desenvolvimento econômico. Em torno do crescente processo de industrialização, há um acirramento das discussões ambientais, que ora configurava-se como um campo de conflitos políticos e sociais.

O Clube de Roma no ano de 1972 publica o relatório "Limites do Crescimento" para denunciar o esgotamento dos recursos naturais, provocando debates em nível mundial. Segundo Ferreira (2006, p.32):

No clima de sensibilidade à questão que se instaurou, proliferaram várias associações ligadas às questões ambientais.

A amplitude mundial do fenômeno é testemunhada pela Primeira Conferência das Nações Unidas sobre o Ambiente, que teve lugar em Estocolmo em 1972. 
Em 1987, com o relatório de Brundtland, a Comissão Mundial Sobre Meio Ambiente e Desenvolvimento (CMMAD) refere ao conceito de Desenvolvimento Sustentável como "um processo de mudança no qual a exploração dos recursos, a orientação dos investimentos, os rumos do desenvolvimento tecnológico e a mudança institucional estão de acordo com as necessidades atuais e futuras" (NOSSO FUTURO COMUM, 1991, p.10).

A criação de um Programa Internacional de Educação Ambiental (PIEA) em 1972 recomendado pela Conferência das Nações Unidas sobre o Meio Ambiente Humano, Estocolmo, provocou a realização do Seminário de Educação Ambiental Internacional em Belgrado, em 1975. Os três importantes eventos que envolvem a história da Educação Ambiental, o de Tibilisi (1977), o Clube de Roma (1968) e o do Rio de Janeiro (1992), todos apontam para a Educação Ambiental inserida em uma dinâmica relacional e complexa. Deste modo, a Educação Ambiental passa a integrar as ações do governo em alguns países, o que implica no interesse de manutenção do status quo.

A partir desses debates dos anos de 1970, 1980 e 1990, a questão ambiental é também tratada como social e na contemporaneidade passa a ser denominada de questão socioambiental. Lima (2005, p.26) afirma:

[...] à conjunção histórica em que o meio ambiente deixou de ser visto e entendido apenas como habitat social, fonte de recursos naturais e espaço para deposição de resíduos associados à atividade econômica, para ser tratado como problema social que requer atenção, cuidado, reflexão e intervenção por parte da sociedade. A problematização das relações entre a sociedade e o ambiente e a nova consciência daí resultante atribuíram um novo significado e estatuto ao meio ambiente, constituindo uma "questão ambiental" onde antes não havia.

No Brasil e na América Latina os movimentos ecológicos ou ambientais surgem por volta dos anos de 1970 em meio a um contexto marcado pela luta por democracia, pois o nosso país neste período vivia a Ditadura Militar, momento em que a repressão política era o lema do Brasil. Para Carvalho (2006, p.49-50):

Ainda que as primeiras lutas ecológicas no Brasil datem dos anos 70 , é principalmente nos anos 80 , no contexto do processo de redemocratização e abertura política, que entram em cena os novos movimentos sociais, entre eles o ecologismo, com as características contestatórias e libertárias e da contracultura.[...] - movimento ecológico brasileiro compartilha do caráter internacionalizado da luta ambiental. Talvez o melhor exemplo de luta social local que adquiriu dimensões ecológicas e se 
transformou em causa apoiada internacionalmente foi a dos seringueiros da Amazônia, sob a liderança de Chico Mendes. $\mathrm{O}$ que torna isso possível é o fato de a percepção da crise ambiental como questão social ocorrer em uma conjuntura de globalização. O famoso lema ecológico "Agir local, pensar global" já expressa a compreensão de que as realidades locais são profundamente afetadas por ações, decisões e políticas definidas internacionalmente.

O Brasil atravanca nos anos 1950 um processo acelerado de expansão urbano-industrial que tinha como matriz a ênfase no desenvolvimento tecnológico e econômico sendo que este produziu diversas formas de degradação ambiental e social. Segundo Lima (2005, p.32):

A concentração da atividade econômica nos centros urbanos; o êxodo rural-urbano que transferiu a maioria da população do país para cidades sem infraestrutura para recebê-la; o modelo de produção industrial alheio a considerações ambientais; a extrema desigualdade de renda e de oportunidades e a industrialização da agricultura, a partir dos anos 1970, com todas suas consequências perversas sobre o ambiente natural e social, são alguns dos processos que compõem a realidade socioambiental recente do Brasil.

No caso brasileiro, a emergência da questão ambiental está associada aos condicionantes internos e externos que perpassa a formação histórica, econômica, política e cultural do nosso país. Desse modo, vale salientar que o Brasil é marcado com a ascensão da consciência ambiental desde o avanço desenfreado do processo de industrialização que deu maior visibilidade a questão ambiental enquanto uma expressão da questão social. Para Lago (1985) a industrialização brasileira concorreu para o surgimento da questão ambiental aliada a um conjunto de realidades pré-existentes em nossa formação. Por sua vez, Carvalho (2008, p.52) nos diz: "No Brasil, a EA aparece na legislação desde 1973, como atribuição da primeira Secretaria Especial do Meio Ambiente (Sema)."

Sabemos que a emergência da questão ambiental no cenário global e local mobilizou a organização de movimentos sociais que reivindicavam por melhorias de condições de vida no planeta. $\mathrm{Na}$ área ambiental irão se destacar o movimento ecológico e o movimento ambientalista, mais conhecido como ambientalismo.

Logo, o movimento ambientalista é considerado um movimento social que para Scherer-Warren (1999 apud LOUREIRO et al., 2006, p.79) considera que "os movimentos sociais constituem ações coletivas reativas e propositivas que 
ocorrem sob a forma de três modalidades não excludentes: (1) denúncia, protesto e conflito; (2) cooperação, parceria e solidariedade; e (3) construção de utopias societária ou civilizacional".

Nesta direção, a Educação Ambiental configura-se como um movimento político reivindicatório em favor de uma maior publicização da questão socioambiental, o que temos visto acontecer com mais frequência na nossa realidade. Nos últimos anos ela tem sido difundida tanto no âmbito governamental, o que para muitos autores da área legitima o discurso conservador de uma educação ambiental de caráter neoliberal, como pelos movimentos sociais e de educação popular, assumindo uma postura de contrahegemonia.

Neste caso, corroboramos com Guimarães (2006) quando afirma que estamos presos em uma armadilha paradigmática, a qual está também a Educação Ambiental, pois, ora reproduz a ordem social vigente. Em 1999 foi aprovada no Brasil a Política Nacional de Educação Ambiental (PNEA) pela lei 9.795. Este acontecimento foi de suma importância porque legitimou a Educação Ambiental como um componente necessário para a formulação de políticas públicas na área ambiental. Neste documento lei, a educação é compreendida conforme:

Os processos por meio dos quais os indivíduos e a coletividade constroem valores sociais, conhecimentos, habilidades, atitudes e competências voltadas para a conservação do meio ambiente, bem de uso comum do povo, essencial à sadia qualidade de vida e sua sustentabilidade. (Lei 9.795 de 27/04/1999)

Em 2002, a PNEA foi regulamentada pelo Decreto Lei 4.281 tornandose um campo de atuação de diversos setores da sociedade civil, assim como consolidada como um espaço para a formação da epistemologia ambiental. A EA vai passar a se configurar como uma problemática interdisciplinar, havendo até disputas entre as correntes teóricas, para prover soluções para a questão socioambiental. No dizer de Leff (2001, p. 115)

A educação ambiental requer a construção de novos objetos interdisciplinares de estudo através da problematização dos paradigmas dominantes, da formação dos docentes e da incorporação do saber ambiental emergente em novos programas curriculares.

Nesta perspectiva de Leff (2001) compreendemos que a formação de um campo epistemológico da Educação Ambiental é resultante do incansável debate e experiências de pesquisadores, educadores que podem estar localizados em diferentes contextos sociais. 
No tocante a problemática daqueles que lidam com resíduos sólidos não trata somente de um problema de origem técnica, para Zaneti $(2003$, p.20) "é na realidade o resultado de uma sociedade de consumo, que gera não apenas 0 rejeito material, como também o social. Como é o caso das pessoas que se alimentam e vivem do resto e das sobras daqueles que consomem e descartam o que se considera inútil."

No cenário socioambiental, a questão do lixo/resíduos sólidos tem sido abordada como um dos problemas ambientais mais graves. $\mathrm{E}$ segundo alguns ambientalistas, como Layrargues (2002) tem havido um reducionismo da problemática ambiental ao lixo, segundo este autor isto pode ser explicado por um fator ideológico que tem sua raiz na lógica da produção capitalista, onde visase mais a reciclagem ou o reaproveitamento do lixo como condição indispensável para a obtenção do lucro. Assim, no dizer de Zaneti (2003, p. 33)

A questão dos resíduos é hoje uma das maiores preocupações e a maior rubrica de despesas das administrações municipais. Soluções técnicas isoladas resolvem parcialmente o problema, já que na medida em que o tempo decorre, observa-se que a quantidade e a complexidade dos resíduos vêm crescendo transformando-se em grave ameaça ao meio ambiente.

Também salientamos que tais processos que são engendrados pela pedagogia dos 3R's: Reduzir, Reutilizar e Reciclar podem contribuir com a gestão dos resíduos sólidos, mas para isso dever-se-ia priorizar a redução do lixo para uma gestão adequada dos resíduos sólidos.

No que diz respeito à Pedagogia dos 3R's, o discurso ecológico alternativo advoga uma sequência lógica a ser seguida: a redução do consumo deve ser priorizada sobre a reutilização e reciclagem; e depois da redução do consumo, a reutilização deve ser priorizada sobre a reciclagem, conforme salienta o texto do Tratado sobre Consumo e Estilo de Vida. (LAYARARGUES, 2002, p. 185).

Além disso, o Brasil vem adotando providências no campo jurídico, aprovando a Política Nacional de Resíduos Sólidos (PNRS) sob a Lei 9.974 de 2000, cuja foi atualizada no dia 24 de abril de 2009, e dispõe sobre o gerenciamento adequado dos resíduos sólidos, assim como inclui os catadores como cidadãos de direitos, protegendo juridicamente e assegurando as suas necessidades. Esta lei foi um avanço no âmbito de garantir os direitos dos catadores e fruto das reivindicações do Movimento Nacional dos Catadores de Materiais Recicláveis (MNCR), aliado a outros segmentos sociais. 


\section{Mossoró (RN) e a problemática dos resíduos sólidos com a interface para a Educação Ambiental}

Mossoró historicamente é a segunda maior cidade do Estado do Rio Grande, conhecida também como a capital do Oeste Potiguar, conta com uma área de $2.108,5 \mathrm{~km}$. Reconhecida nacionalmente pela fruticultura irrigada, agronegócio, produção de sal e petróleo. As condições edafo-climáticas, características peculiares da região semiárida do nordeste brasileiro, tem sido alteradas pelo grande crescimento urbano da cidade, fator que coopera com o aceleramento das degradações ambientais, é perceptível que tem ocorrido mudanças na realidade mossorensse, pois a temperatura se eleva inviabilizando o cultivo, bem como a colheita de determinadas culturas, tendo como consequência a infertilidade dos solos. Outro problema perceptível é a poluição das águas do rio Apodi-Mossoró, uma das maiores bacias de água-doce da região nordeste do Brasil, tendo suas matas ciliares degradadas, as quais eram responsáveis pela proteção de suas margens.

Quanto a realidade política Mossoró/RN é constituída de um cenário marcado pela família dos Rosados que se mantém no poder há mais de 50 anos, o que pode refletir na gestão local do município e também na cultura do povo mossoroense. Este cenário é composto por diversos atores sociais entre eles: empresas, organizações não-governamentais, partidos políticos, universidades e movimentos sociais.

A municipalidade da Política de Educação Ambiental de Mossoró/RN está em gestação e é permeada por relações conflituosas entre os diversos atores sociais. Entre estes estão os catadores de materiais recicláveis que lutam tanto pelo reconhecimento enquanto profissional que colabora na gestão de limpeza da cidade como também enquanto atores políticos participantes da construção das políticas ambientais. Percebemos que os conflitos em torno da questão ambiental tocam na legitimidade dos catadores enquanto agentes de Educação Ambiental, que não se limitam somente a catar resíduos para sobreviver, mas a atuarem com pequenas transformações no seu dia a dia. Sendo assim, faz-se necessário tecer algumas das experiências observadas em pesquisa participante na Associação Comunitária Reciclando para a Vida.

\section{A Educação Ambiental na perspectiva de catadores de lixo}

Encontramos no universo dos catadores da ACREVI localizada em Mossoró/RN, em que cada um, dada a sua localidade, vive um contexto de segregação e exclusão, onde para sobreviver vão em busca do lixo. Vejo que a problemática do lixo está intimamente ligada a vida desses catadores, pois os mesmos ressignificam o lixo e the atribuem um sentido subjetivo de dependência para a vida. Nós podemos vivenciar esta realidade em uma das nossas visitas a Associação Comunitária Reciclando para a Vida na fala de uma associada: 
Cheguei para pegar o material da coleta em uma casa do bairro e chegando lá perguntei se tinha material, ela gritou pra alguma pessoa e disse para pegar o lixo e aí eu falei, não é lixo senhora, é luxo para nós. Para nós é o que dá o nosso sustento. (DIÁRIO DE PESQUISA, ASSOCIADA I, SIC).

A fala acima traz alguns elementos que tocam na relação sociedade/natureza, na cultura local e no processo de produção de novos conhecimentos, semeados em sua dimensão popular. Encontramos inicialmente uma contradição nesta relação sociedade/natureza, por ser apropriada como espaço de exploração e acumulação de capital, ou até mesmo reduzida a um conflito meramente econômico. Depois, percebemos que essa relação de contradição dialoga diretamente com a cultura de cada pessoa, neste estudo de cada catador, de suas subjetividades e identidades, sem estas, novos conhecimentos e saberes permaneceriam ocultos pelos processos de monoculturas científicas. Por isso, consideramos importante dar voz as trajetórias de alguns destes catadores, traçando um itinerário: de onde são, quem são e o que pensam.

A ACREVI surgiu na comunidade Nova Vida, município de Mossoró/RN, no ano de 1999, por iniciativa de catadores de lixo, composta em sua maioria por mulheres, tendo Josefa Avelino Silva como presidenta. Esta associação é permeada por algumas questões que merecem destacar: a questão ecológica, a educação popular e a formação política de seus componentes. Seu surgimento se dá num contexto de retirada dos lixões que rodeavam as periferias da cidade, como também inserção dos mesmos no mercado de trabalho informal. A dimensão ecológica que gera em cada catador o pertencimento e compromisso pró-ecológico no cuidado do meio ambiente, se expressa nas práticas de Educação Ambiental. Como abaixo foi sinalizado.

Quando questionamos uma associada sobre a compreensão da educação ambiental ela revelou que a:

Educação Ambiental é poder limpar o meio ambiente. (ASSOCIADA I).

Aqui, identificamos uma concepção voltada para a preservação do meio ambiente, que para Sauvé (2005) é vê a natureza como algo puro, original que deve ser respeitada. Atentamos que dentro desta sociabilidade a relação sociedade/natureza é mediada pelo conflito, em que a humanidade tem exercido um poder descontrolado sobre a natureza para a obtenção de grandes lucros. Por outro lado, também existe a formação de uma consciência de cuidado com o ambiente físico. O que poderia até suscitar a formação de novas estratégias de Educação Ambiental que ultrapassem a fatalidade da relação 
pessoa/ambiente, pois mesmo que haja conflito, há também uma relação de interdependência e de sobrevivência.

Tratar a natureza apenas como recurso que pode ser utilizada para necessidades urgentes, retira a importância de valorizá-la enquanto outro ser vivo que mantém a vida do planeta, numa inter-relação com a humanidade. Esquecendo-se deste detalhe, muitos pesquisadores permanecem muitos mais ligados a uma discussão ideológica, do que de fato comprometidos com a formação humana, política nos diversos espaços da sociedade. Logo, a mesma possibilidade que temos de nos comprometer com as causas ambientais, também temos de formar na humanidade uma cultura de paz, destinada ao futuro que começa no aqui e no agora e no investimento na Educação Ambiental Popular.

A Educação Ambiental é vista como um meio de gerar renda por meio do processo da sensibilização da comunidade. Isto também vai de contra a articulação que a ACREVI vem fazendo com as manifestações sociais em prol de uma sociedade mais justa, assim como fragiliza a ideia de Educação Ambiental Popular, crítica, pois ela acaba sendo usada para reproduzir a ideologia social capitalista, conforme nos expõe Layrargues (2003) a Educação Ambiental vive um certo dualismo, entre as posturas crítica e conservadora. Josefa referindo-se a isso, expressa-se

[...] O dinheiro não é tudo é o que tenho falado para os catadores da ACREVI, é preciso aliar o dinheiro ao conhecimento, pois o conhecimento pode transformar mais que o dinheiro (DIÁRIO DE PESQUISA, SIC).

A associada acima aponta a necessidade de formação dos catadores e não só ganhar dinheiro, o que nos leva a pensar no sentido da construção de um conhecimento pertinente, de um conhecimento vivido, como afirmam Morin (2001) e Freire (1999), ou um conhecimento prudente para uma vida descente, como defende Santos (2008). Este conhecimento que a catadora acima pode ser concretizado quando saímos dos muros da academia, das vaidades dos títulos e colocamos a humildade como parte das trajetórias de cada pessoal envolvida no fazer ciência, uma ciência que não está distante da vida, que não está distante também da academia. Um ponto que se destaca dentro desta interpretação é que se continua a colonizar o conhecimento acadêmico, omitindo-se a criatividade dos múltiplos atores. Logo, descobre-se neste processo que a ecologia pode ser o elemento necessário para reinventar a economia, ou melhor reinventar a humanidade, resgatar a humanidade do materialismo e do consumismo tão impregnados também na cultura científica.

Outra entrevistada nos informa sobre o que é a Educação Ambiental, a associada nos diz: 
[...] É a gente aprender a ser educado com o meio ambiente, tirar a sujeira do meio das ruas.

A visão predominante entre os catadores associados acerca da EA é de vê-la como uma ferramenta para acabar com o lixo, através da sensibilização. Sabemos que a EA vai muito, além disso, dado o seu universo consolidado enquanto política pública e que somente "a Educação Ambiental não será capaz de erradicar o problema dos resíduos sólidos. Porém, acreditamos que estas opiniões estão marcadas pela experiência cotidianas e que, portanto, os associados falam daquilo que vivem. Sposati $(1998$, p. 3) considera:

Partimos do ponto em que a associação assume um papel socioeconômico- cultural frente aos catadores, despertando-os para o seu envolvimento e intervenção na realidade socioambiental de suas comunidades.

Nesse sentido, é importante ressaltar que a EA é necessária para a melhoria da qualidade de vida das pessoas da ACREVI, assim como, pode potencializar os seus conhecimentos e ações. Identificamos isto na fala da presidenta da ACREVI:

Com certeza, o conhecimento é muito interessante. É como eu disse tem a prática, mas é preciso a parte teórica, né, isso é muito importante. Eu queria que elas fossem como eu, porque tudo a gente consegue, com o conhecimento. As vezes a gente corre atrás mais de dinheiro, mas eu digo vá primeiro atrás do conhecimento que tudo vem com ele. Eu vejo mudança na vida dos associados, a gente discute coisas que não se discutia antes. O próprio preconceito que a gente enfrentou, mas muitas entenderam que isso é um trabalho digno. Temos muita coisa hoje (PRESIDENTA DA ACREVI).

A relação entre o conhecimento e as ações é percebida pela catadora acima como de suma relevância para o seu desenvolvimento pessoal. A partir deste informe pode se desvendar que o catador assume uma identidade de transformador social por meio da produção de novas ecopráxis, o que valoriza o saber popular e aproxima a ciência da vida. Outro aspecto que pode ser capturado da fala acima é que o envolvimento com a temática ambiental possibilitou a emergência da Educação Ambiental enquanto política que compromete com a justiça ambiental. Isto é visível quando os catadores passam a se envolver com as questões relacionadas ao desenvolvimento da cidade, se 
antes eram catadores de materiais recicláveis, por meio disto podem atuar como Educadores Ambientais.

O compromisso pró-ecológico desenvolvido nas práticas de Educação Ambiental pode ser fragilizado quando na organização de um grupo que defende causas ambientais, um dos componentes monopoliza as opiniões acerca do processo, o que gera competição no trabalho coletivo. Isso foi constatado na ACREVI, quando presenciamos, em muitas reuniões que o número de despolitizados eram enormes, e que em virtude disto alguns começavam a aderir a lógica de rendas diferentes, mesmo trabalhando em uma associação sob a direção da economia solidária.

É importante salientar que não se pode culpabilizar as pessoas que constituem a ACREVI por contradições que aparecem no cotidiano de suas atividades, tais incoerências servem para gerar experiências de esperança em uma cultura mais humana, em que a partilha e a unidade serão as pontes do verdadeiro desenvolvimento sustentável.

\section{(In)conclusão: catando algumas palavras para além do lixo}

A nossa investigação reafirma que a Educação Ambiental é um campo fértil que vem motivando pesquisadores de várias áreas do conhecimento para além dos ambientalistas a formarem conhecimentos sobre a relação sociedadenatureza e pessoa-ambiente. Neste sentido, a proposta de pesquisa sobre a Educação Ambiental nos inquietava há alguns anos e procuramos encontrar no cenário da ACREVI em Mossoró/RN, conhecimentos sobre a questão.

Sabendo que a problemática do lixo está intrinsecamente vinculada a história dos catadores, constatamos a necessidade de uma dimensão socioeducativa para uma possível redução dos resíduos. Analisamos como os catadores e catadoras da ACREVI compreendem a educação ambiental nas ações realizadas no seu cotidiano nos bairros da cidade.

Nas concepções dos seis associados entrevistados sobre EA percebemos que há criticidade, pois, os mesmos, expressam sua indignação com a realidade que vive. Identificamos também por meio das análises a formação de um saber ambiental no interior do grupo, bem como a disponibilidade dos mesmos para cooperar com o trabalho. Como também, identificou-se contradições que são próprias das relações sociais permeadas por conflitos e interesses econômicos.

No nível das dificuldades e desafios vemos que o estigma de inferioridade ainda ronda os catadores, porém tem se dado passos de rompimento quando os mesmos se reconhecem minimamente como pessoas de direitos. Como desafio, está uma gestão que necessita de organização e uma formação que os capacite para compreender o papel da ACREVI que não é só 
gerar renda, mas qualificar o humano e torná-los verdadeiros agentes de educação ambiental. Constatamos a necessidade de os associados estudarem e compreenderem o Estatuto da ACREVI para que saibam das suas funções, direitos e deveres.

No nível da relação entre a ACREVI e a gestão municipal do meio ambiente em Mossoró (RN) percebe-se que é mediada por conflitos e interesses diferentes que constituem o cenário do controle social e da participação na gestão democrática do meio ambiente. Destaca-se como perceptível a competição da ACREVI com outras associações que foram emergindo e utilizadas para prestarem serviços mais baratos a prefeitura municipal em Mossoró (RN).

Sugere-se como um caminho de superação e de amadurecimento da Política de Educação Ambiental em Mossoró (RN) a promoção de diálogos entre os diferentes atores que a constituem. Ampliar a ressocialização de informações da gestão pública local por meio dos diversos meios de comunicação social. E por último, alimentar a relação entre a ciência-meio ambiente e vida com a esperança de construirmos uma civilização verdadeiramente humana, que começa ao se apropriar dos seus erros e equívocos, para gerar uma relação de pertencimento mais profunda, afetiva e política.

\section{AGRADECIMENTOS}

Agradeço aos professores: Geovânia da Silva Toscano (Orientadora), Ramiro Valera Camicho e Gilcélia Batista de Góis, que constituíram e minha banca de TCC e me estimularam a prosseguir na esperança de construir um mundo melhor pleno de cuidado.

\section{REFERÊNCIAS}

BRASIL. Lei n. 9. 795 de 27 de abril de 1999. Dispõe sobre a educação ambiental, institui a Política Nacional de Educação Ambiental e dá outras providencias. Ministério do Meio Ambiente. Consultoria Jurídica. In: Legislação Ambiental Básica. Brasília: Ministério do Meio Ambiente, UNESCO, 2008. p. 199202.

CARVALHO, I.C.M.C. Educação ambiental: a formação do sujeito ecológico. 3 ed. São Paulo: Cortez, 2008.

CARVALHO, I.C.M.C. A questão ambiental e a emergência de um campo de ação político-pedagógica. In: LOUREIRO, C.F.B; LAYRARGUES, P.P.; CASTRO, R.S. (orgs). Sociedade e Meio Ambiente: a educação ambiental em debate. 4. ed. São Paulo: Cortez, 2006. p.54-65.

COMISSÃO Mundial Sobre o Meio Ambiente e Desenvolvimento - CMMAD. Nosso Futuro comum. Tradução de "Our Common future". 2 ed. Rio de Janeiro, RJ: Fundação Getúlio Vargas, 1991. 
FERREIRA, L.C. Ideias para uma Sociologia da Questão Ambiental no Brasil. São Paulo: Annablume, 2006.

FIGUEIREDO, J.B.A. Educação Ambiental dialógica e representações sociais da água em cultura sertaneja nordestina: uma contribuição à consciência ambiental em Irauçuba - CE (Brasil). São Carlos-SP: UFSCar, 2003. Tese (Doutorado em Educação Ambiental).

FOLADORI, G. O Capitalismo e a crise ambiental. Raízes, ano XVIII, № 19. Curitiba, 1999.

GUIMARÃES, M. Armadilha paradigmática na educação ambiental. In: LOUREIRO, C.F.B. et al. Pensamento Complexo, dialética e educação ambiental. São Paulo: Cortez, 2006.

LAYRARGUES, P. O cinismo da reciclagem: o significado ideológico da lata de alumínio e suas implicações para a educação ambiental. In: LOUREIRO, C.F.B. et al. Educação Ambiental: repensando o espaço da cidadania. 2 ed. São Paulo: Cortez, 2002.

LAGO, A.; PÁDUA, J.A. O que é Ecologia. São Paulo: Brasiliense, 1985.

LEFF, E. Saber ambiental: sustentabilidade, racionalidade, complexidade. Trad. de Lúcia Mathilde Endlich Orth. 5. ed.Rio de Janeiro: Vozes, 1999.

LIMA, G.F.C. Formação e dinâmica do campo da Educação Ambiental no Brasil: emergência, identidades, desafios. Campinas(SP): UEC, 2005. (Tese de Doutorado em Ciências Sociais).

LOUREIRO, C.F. Teoria Social e Questão Ambiental: pressupostos para uma práxis crítica em Educação Ambiental. In: LOUREIRO, C.F.B; LAYRARGUES, P.P.; CASTRO, R.S. (orgs). Sociedade e Meio Ambiente: a educação ambiental em debate. 4. ed. São Paulo: Cortez, 2006. p. 07-51.

MORIN, E. Terra-Pátria. Lisboa: Instituto Piaget, 2001.

SAUVÉ, L. Cartografias da Educação Ambiental. In: SATO, M.; CARVALHO, I.(Org.). Pesquisa em Educação Ambiental. São Paulo: Rima, 2005.

SOFFIATI, A. Fundamentos filosóficos e históricos para o exercício da ecocidadania e da ecoeducação. In: LOUREIRO, C.F.B.; LAYRARGUES, P.P.; CASTRO, R.S. (Org.). Educação Ambiental: repensando o espaço da cidadania. 2 ed. São Paulo: Cortez, 2002.

SPOSATI, A.O. SER SOCIAL, No. 55, ano XVI, 1998.

ZANETI, I. Educação Ambiental, Resíduos Sólidos Urbanos e Sustentabilidade. Um estudo de caso sobre o sistema de gestão de Porto Alegre-RS. Brasília: UnB, 2003. (Tese de Doutorado em Desenvolvimento Sustentável). 